\title{
Influence of Titanium on Microstructure, Phase Formation and Wear Behaviour of AlCoCrFeNiTi High-Entropy Alloy
}

\author{
Martin Löbel *, Thomas Lindner, Thomas Mehner and Thomas Lampke \\ Materials and Surface Engineering Group, Institute of Materials Science and Engineering, \\ Chemnitz University of Technology, D-09125 Chemnitz, Germany; th.lindner@mb.tu-chemnitz.de (T.Li.); \\ thomas.mehner@mb.tu-chemnitz.de (T.M.); thomas.lampke@mb.tu-chemnitz.de (T.La.) \\ * Correspondence: martin.loebel@mb.tu-chemnitz.de; Tel.: +49-371-531-31865
}

Received: 31 May 2018; Accepted: 29 June 2018; Published: 2 July 2018

\begin{abstract}
The novel alloying concept of high-entropy alloys (HEAs) has been the focus of many recent investigations revealing an interesting combination of properties. Alloying with aluminium and titanium showed strong influence on microstructure and phase composition. However, detailed investigations on the influence of titanium are lacking. In this study, the influence of titanium in the alloy system $\mathrm{AlCoCrFeNiTi}$, was studied in a wide range (molar ratios $\mathrm{x}=0.0 ; 0.2 ; 0.5 ; 0.8 ; 1.0$; 1.5). Detailed studies investigating the microstructure, chemical composition, phase composition, solidification behaviour, and wear behaviour were carried out. Alloying with titanium showed strong influence on the resulting microstructure and lead to an increase of microstructural heterogeneity. Phase analyses revealed the formation of one body-centred cubic (bcc) phase for the alloy without titanium, whereas alloying with titanium caused the formation of two different bcc phases as main phases. Additional phases were detected for alloys with increased titanium content. For $x \geq 0.5$, a minor phase with face-centred cubic (fcc) structure was formed. Further addition of titanium led to the formation of complex phases. Investigation of wear behaviour revealed a superior wear resistance of the alloy $\mathrm{AlCoCrFeNiTi}{ }_{0.5}$ as compared to a bearing steel sample.
\end{abstract}

Keywords: HEA; high-entropy alloy; CCA; compositionally complex alloy; phase composition; microstructure; wear behaviour

\section{Introduction}

High-entropy alloys (HEAs) are an emerging class of new materials. Their alloying concept differs from conventional alloys, which are composed of one main element, and an improvement of properties is achieved by adding minor amounts of other elements. In contrast, HEAs are multicomponent alloys comprising at least five elements with approximately equimolar composition [1]. Despite their complex composition, only simple solid solutions with fcc or bcc structure were formed for several alloy systems. The formation of brittle and intermetallic phases can be successfully suppressed. One of the first alloys with a single fcc phase is the equimolar alloy CoCrFeMnNi investigated by Cantor et al. [2]. Due to their unique structure, HEAs exhibit an interesting combination of properties e.g., high hardness and strength in combination with adequate ductility. Furthermore, a high wear and corrosion resistance can be obtained [3-6]. Two main groups can be distinguished: HEAs forming (i) cubic or (ii) hexagonal phases [4].

Detailed structural investigations of HEAs revealed that only a few alloys form a single phase microstructure comprising fcc or bcc phases. Most alloys are composed of more than one phase, partly including complex or intermetallic phases. For these alloys, the term compositionally complex alloys (CCA) was introduced [7]. 
One of the most intensely investigated HEA systems, primarily forming cubic phases is AlCoCrCuFeNi $[8,9]$. Due to the positive enthalpy of mixing $\Delta \mathrm{H}_{\text {mix }}$ among $\mathrm{Cu}$ and the elements $\mathrm{Fe}$ and $\mathrm{Cr}$, segregation was observed, deteriorating mechanical and corrosion properties. Therefore, subsequent investigations focused on the copper-free derivative AlCoCrFeNi [3,10-13]. Early studies concentrated on the equimolar composition. However, investigations showed that optimum properties are usually achieved when choosing a differing chemical composition [14].

Investigating the influence of different alloying elements showed a strong influence of aluminium on the microstructure, phase composition, and properties [15,16]. For a low aluminium content, fcc phases are stabilised, whereas high contents of aluminium act as a strong bcc phase stabiliser [17,18]. In addition, the formation of complex phases can be suppressed for a high aluminium content [19].

Furthermore, the influence of additional alloying elements has been investigated. One element which shows distinct effects on microstructure, phase composition, and mechanical properties is titanium. Due to its large atomic radius, titanium leads to solid solution strengthening, increasing its hardness and strength. However, for a high titanium content, the formation of intermetallic phases and compounds was determined, leading to embrittlement. The alloy system AlCoCrFeNiTi shows high wear resistance also in comparison to conventional steels [20-24].

Detailed investigations on the influence of the alloying element titanium are required for the development of lightweight HEAs. The aim of the present study is the determination of the influence of this alloying element in the alloy system $\mathrm{AlCoCrFeNiTi}_{x}$ regarding its influence on microstructure, phase composition and wear behaviour.

\section{Materials and Methods}

Bulk samples of the alloy system AlCoCrFeNiTi $x_{x}$ with the molar ratios of $x=0.0 ; 0.2 ; 0.5 ; 0.8$; $1.0 ; 1.5$ were produced by arc-melting. Elemental granules with a purity of $\geq 99.9 \%$ were used as raw materials. The elemental granules were weighed and mixed according to the intended molar ratios. Each sample had a total weight of $10 \mathrm{~g}$. Arc-melting of the samples was conducted in a water-cooled copper crucible.

After evacuating and reaching a pressure of $2 \times 10^{-4} \mathrm{mbar}$, the furnace chamber was filled with argon to a pressure of 1.1 bar. A tungsten electrode was used to ignite an arc. All samples were remoulded three times and turned after each step to achieve chemical homogeneity. The resulting samples had a diameter of approximately $20 \mathrm{~mm}$. For the arc furnace, a low cooling rate of $<50 \mathrm{~K} / \mathrm{s}$ was determined in preliminary studies.

Metallographic cross-sections were prepared according to standard metallographic procedures. Investigations of the microstructure were carried out by scanning electron microscopy (SEM) in a LEO 1455VP (Zeiss, Jena, Germany) with an acceleration voltage of $25 \mathrm{kV}$. For the visualisation of material contrast, a backscattered-electron detector (BSD) was used. The analyses of the overall chemical composition was carried out by energy dispersive X-ray spectroscopy (EDS) with a GENESIS spectrometer (EDAX, Mahwah, NJ, USA) at a magnification of $500 \times$ within an analysis area of approximately $43,500 \mu \mathrm{m}^{2}$. Three measurements were carried out for every sample. Microhardness measurements (Vickers hardness HV0.5) were conducted with a Wilson Tukon 1102 device (Buehler, Uzwil, Switzerland) in metallographic cross-sections. The average microhardness and standard deviation was calculated from ten single indents. Phase analyses was conducted by X-ray diffraction (XRD) with a D8 Discover diffractometer (Bruker AXS, Billerica, MA, USA) using Co K $\alpha$ radiation (tube parameters: $40 \mathrm{kV} ; 40 \mathrm{~mA}$ ). The diffractograms were measured in a diffraction angle range $(2 \theta)$ of $20^{\circ}$ to $130^{\circ}$ with a step size of $0.01^{\circ}$ and $3.4 \mathrm{~s} / \mathrm{step}$, which corresponds to $653 \mathrm{~s} / \mathrm{step}$ due to the utilisation of a 1D Lynxeye XE detector. For phase identification, the powder diffraction file (PDF) database 2014 (International Centre for Diffraction Data) was used. The solidification behaviour was investigated by differential scanning calorimetry (DSC) with a STA 409 C device (Netzsch, Selb, Germany) under argon atmosphere in the temperature range from $1800 \mathrm{~K}$ to room temperature with a cooling rate of $20 \mathrm{~K} / \mathrm{min}$. 
To investigate the tribological behaviour under adhesive, oscillating, and abrasive wear conditions, ball-on-disk, oscillating wear and scratch tests have been carried out. For the ball-on-disk tests a Tetra Basalt Tester (Tetra, Ilmenau, Germany) were used. The oscillating wear tests were carried out with a Wazau SVT 40 device (Wazau, Berlin, Germany) and a CSM Revetest-RST device (CSM Instruments SA, Peseux, Switzerland) has been used for the scratch tests. The applied parameters are summarised in Table 1.

Table 1. Wear test parameters.

\begin{tabular}{|c|c|c|c|c|c|}
\hline \multicolumn{2}{|c|}{ Ball-on-Disk Test } & \multicolumn{2}{|c|}{ Oscillating Wear Test } & \multicolumn{2}{|c|}{ Scratch Test } \\
\hline Force & $20 \mathrm{~N}$ & Force & $26 \mathrm{~N}$ & Mode & progressive \\
\hline Radius & $5 \mathrm{~mm}$ & Frequency & $40 \mathrm{~Hz}$ & Force & $1-200 \mathrm{~N}$ \\
\hline Speed & 96 RPM & Time & $900 \mathrm{~s}$ & Speed & $2.5 \mathrm{~mm} / \mathrm{min}$ \\
\hline Cycles & 15916 & Amplitude & $0.5 \mathrm{~mm}$ & Length & $5 \mathrm{~mm}$ \\
\hline Counter body & $\mathrm{Al}_{2} \mathrm{O}_{3}$ & Counter body & $\mathrm{Al}_{2} \mathrm{O}_{3}$ & Tip & Rockwell C \\
\hline Diameter & $6 \mathrm{~mm}$ & Diameter & $10 \mathrm{~mm}$ & Radius & $200 \mu \mathrm{m}$ \\
\hline
\end{tabular}

The measurements of the resulting wear depths after the ball-on-disk test were conducted by a contact stylus instrument with a Hommel Etamic T8000 device (Jenoptik, Villingen-Schwenningen, Germany). Resulting wear marks of the oscillating wear and scratch tests were analysed by laser scanning microscopy (LSM) with a Keyence VK-X200 device (Keyence, Osaka, Japan) to determine the resulting wear depth. The reference material bearing steel EN 1.3505 (100Cr6) was investigated under identical conditions. Wear marks of the scratch test were investigated with the digital microscope Keyence VHX-500 (Keyence, Osaka, Japan).

\section{Results and Discussion}

\subsection{Chemical Composition}

The mean chemical composition of all samples was measured. Results are summarised in Table 2.

Table 2. Mean chemical composition (in at.\%) of AlCoCrFeNiTi samples, measured by EDS and nominal values. The measured chemical compositions are in good agreement with the target compositions.

\begin{tabular}{|c|c|c|c|c|c|c|c|}
\hline $\mathbf{x}$ & & Al & Co & $\mathrm{Cr}$ & Fe & $\mathbf{N i}$ & $\mathbf{T i}$ \\
\hline \multirow[b]{2}{*}{0.0} & nominal & 20.0 & 20.0 & 20.0 & 20.0 & 20.0 & 20.0 \\
\hline & measured & 21.3 & 19.4 & 19.9 & 19.9 & 19.5 & 0.0 \\
\hline \multirow[b]{2}{*}{0.2} & nominal & 19.2 & 19.2 & 19.2 & 19.2 & 19.2 & 3.9 \\
\hline & measured & 20.3 & 18.9 & 19.0 & 19.2 & 18.7 & 3.9 \\
\hline \multirow{2}{*}{0.5} & nominal & 18.2 & 18.2 & 18.2 & 18.2 & 18.2 & 9.1 \\
\hline & measured & 20.0 & 17.8 & 17.4 & 17.6 & 18.2 & 9.0 \\
\hline \multirow{2}{*}{0.8} & nominal & 17.2 & 17.2 & 17.2 & 17.2 & 17.2 & 13.8 \\
\hline & measured & 19.0 & 16.7 & 16.8 & 16.7 & 17.3 & 13.5 \\
\hline \multirow{2}{*}{1.0} & nominal & 16.7 & 16.7 & 16.7 & 16.7 & 16.7 & 16.7 \\
\hline & measured & 17.9 & 16.2 & 16.7 & 16.6 & 16.4 & 16.3 \\
\hline \multirow{2}{*}{1.5} & nominal & 15.4 & 15.4 & 15.4 & 15.4 & 15.4 & 23.1 \\
\hline & measured & 16.7 & 15.2 & 15.4 & 15.3 & 15.6 & 22.0 \\
\hline
\end{tabular}

The chemical composition of the arc-melted samples was in good agreement with the nominal values. Only for the aluminium content did a distinct deviation of $>1$ at. $\%$ occur. The titanium content was in good agreement with the nominal values for all samples. 


\subsection{Microstructure}

SEM images of the microstructure using a BSD to visualise material contrast with different magnifications are shown in Figure 1.

(a)
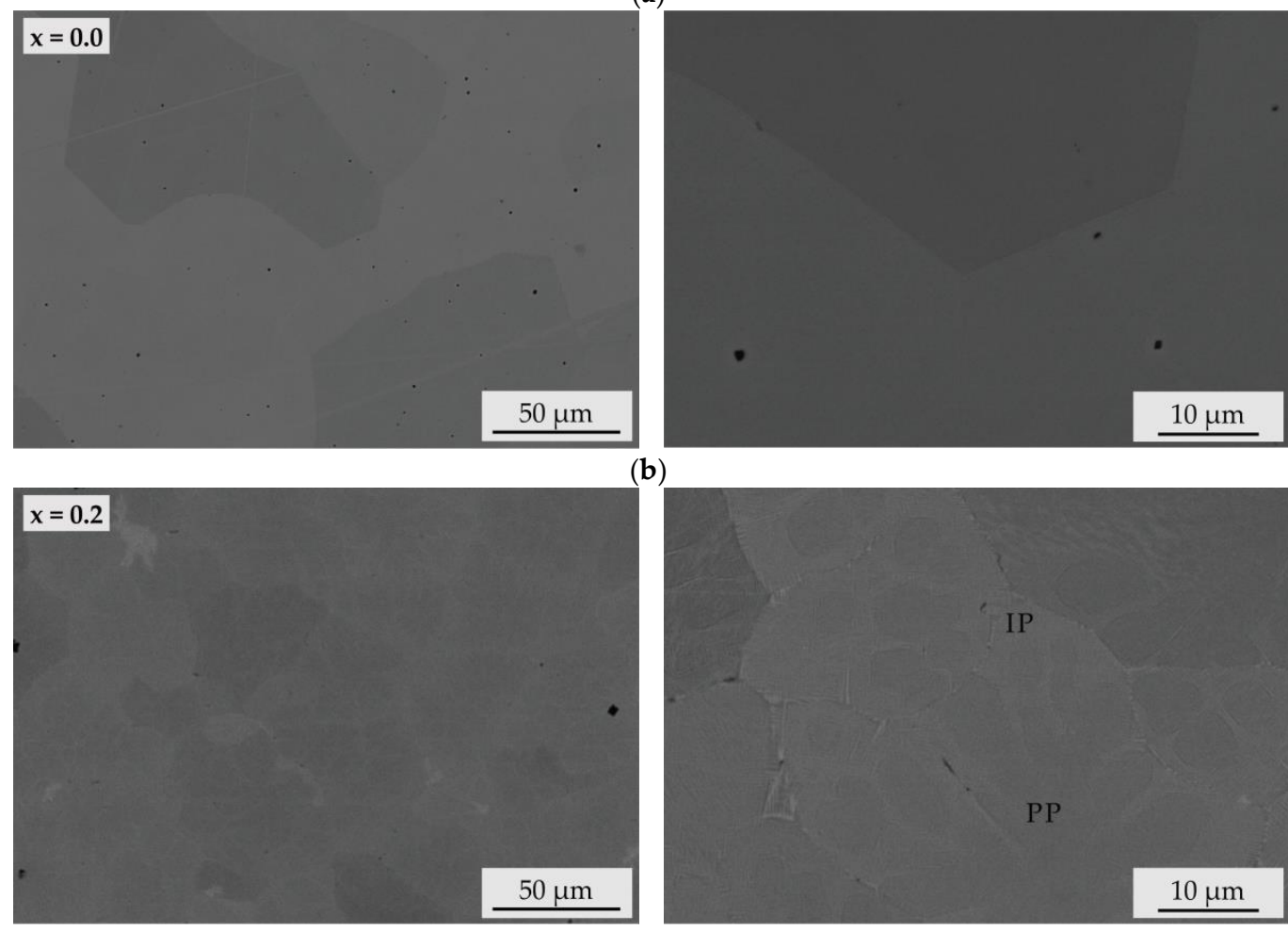

(c)
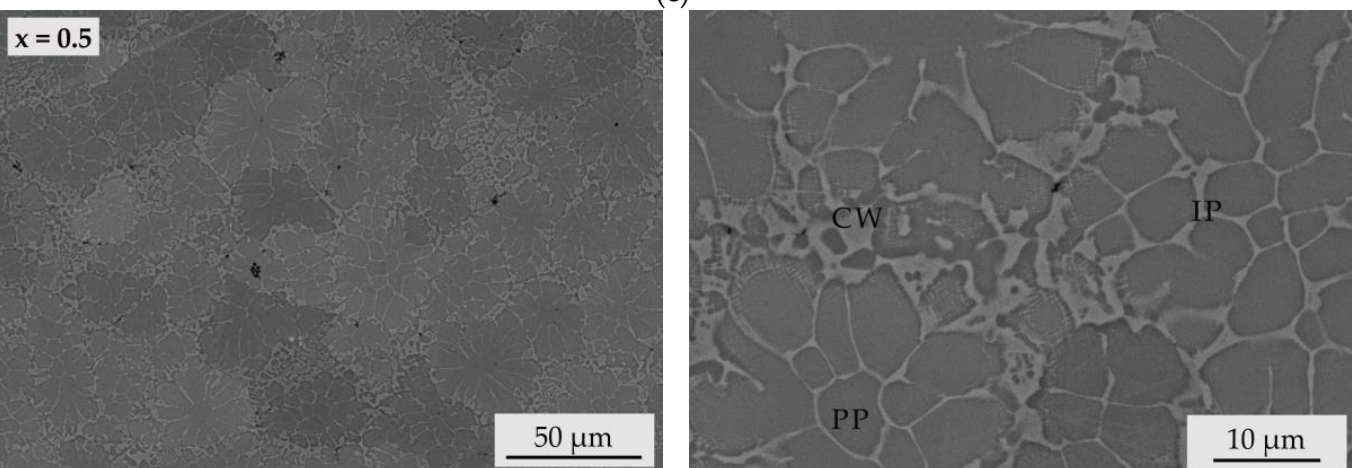

(d)
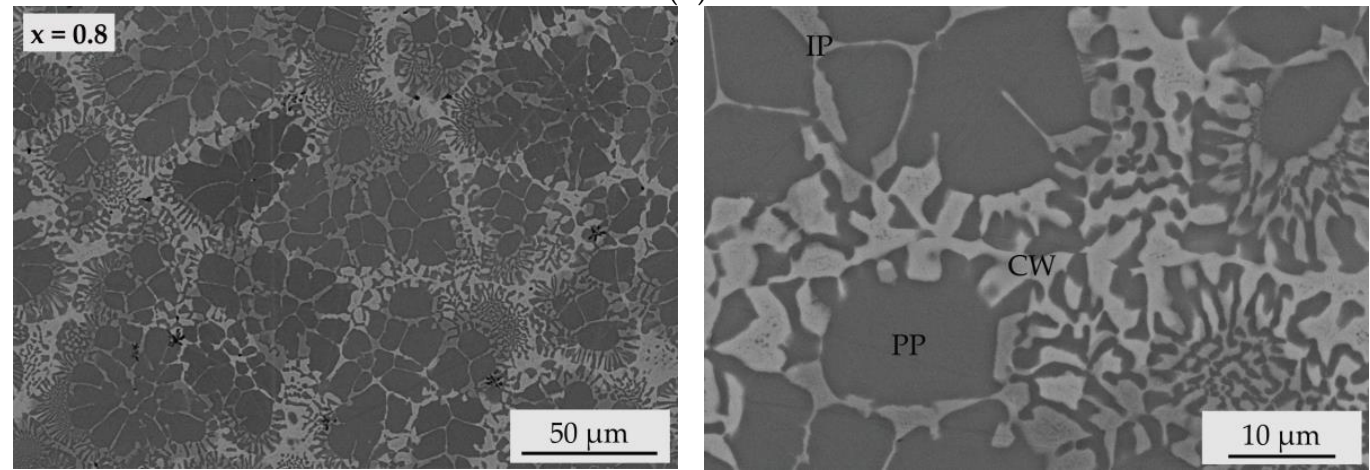

Figure 1. Cont. 
(e)
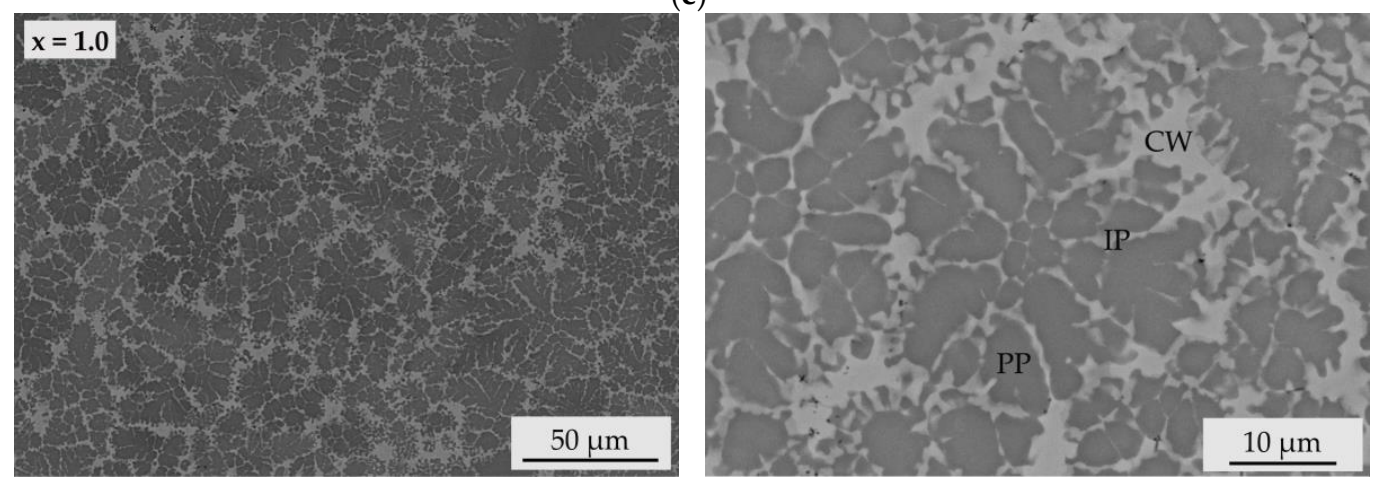

(f)
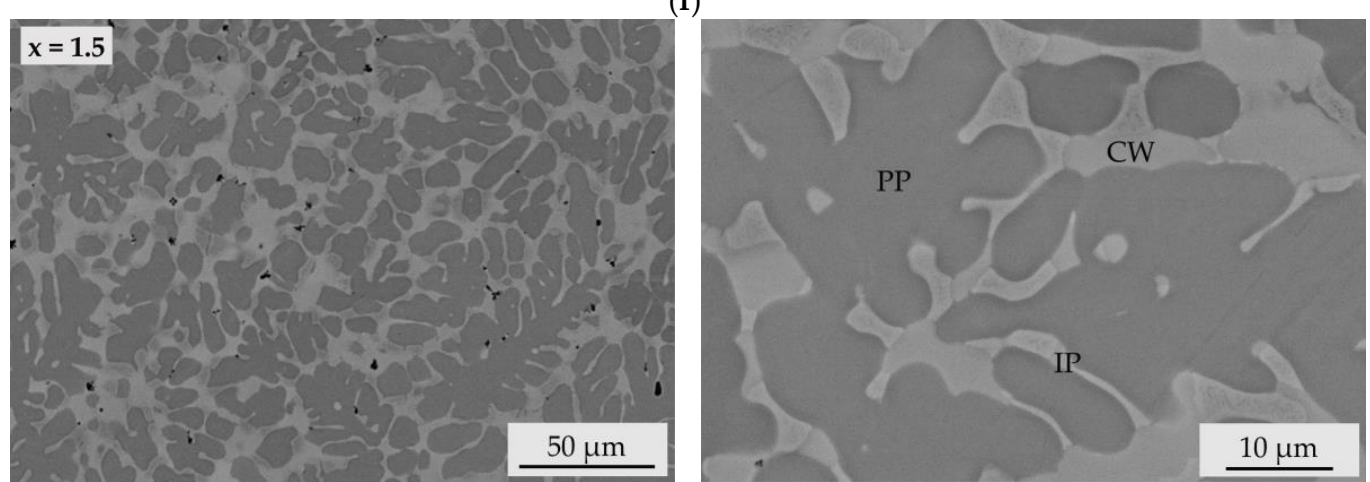

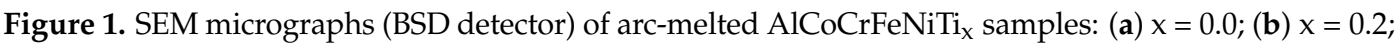
(c) $\mathrm{x}=0.5 ;(\mathbf{d}) \mathrm{x}=0.8 ;(\mathbf{e}) \mathrm{x}=1.0 ;(\mathbf{f}) \mathrm{x}=1.5$ with phase declaration (PP: primary phase; CW: cell wall; IP: interdendritic phase). The formation of additional phases and an increase of heterogeneity in the microstructure can be observed for an increased titanium content.

For the alloy without titanium $(x=0.0)$, a homogeneous microstructure occurred. The grains solidified with no preferred direction. Low differences of the chemical composition were confirmed by a minor BSD contrast. Alloying with titanium causes the formation of a more heterogeneous microstructure. Within the grains, material contrast was observed for the alloy with $x=0.2$, indicating differences in the chemical composition. Between both of these areas, no distinct boundaries occurred, indicating a directional solidification with minor change in orientation. During the solidification, the precipitation of the primary phase caused a depletion of alloy elements in the residual liquid phase, causing the precipitation of a secondary phase with a different chemical composition. With further increased titanium content $(x=0.5)$, a dendritic structure appeared. A bright-appearing phase (interdendritic phase) was observed at the grain boundaries of the primary phase, indicating that this area is rich in elements with a high atomic number. A third phase (cell wall) solidifies as a remainder between the dendritic structures. For the alloy with higher titanium content $(x=0.8)$, the content of this third phase increased. Also, for the samples with further increased titanium content $(x=1.0$ and $x=1.5$ ), a dendritic structure comprising three distinguishable phases appeared. The cross-sections of all arc-melted samples exhibited cavities and shrinkage porosity caused by a different contraction of the present phases, and small amounts of breakouts due to the metallographic preparation or sample production (black areas). The presence of these defects was most distinct for the alloy with the highest titanium content $(\mathrm{x}=1.5)$.

\subsection{Solidification Behaviour and Phase Analyses}

The solidification behaviour was determined by DSC measurements. The resulting cooling curves in a temperature range of $1800 \mathrm{~K}$ to $800 \mathrm{~K}$ are shown in Figure 2. 


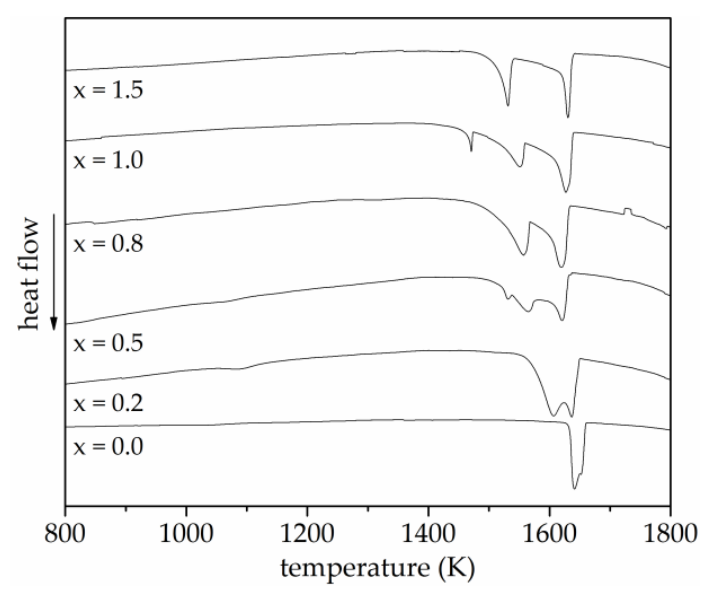

Figure 2. DSC cooling curves of arc-melted $\mathrm{AlCoCrFeNiTi}_{\mathrm{x}}$ samples. A single exothermic reaction can be observed for the alloy without titanium, whereas several exothermic reactions occur for all alloys containing titanium, revealing the formation of additional phases.

The DSC cooling curve of the alloy without titanium $(x=0.0)$ exhibited one peak at a temperature of $1640 \mathrm{~K}$. All investigated alloys showed a major peak at a temperature above $1600 \mathrm{~K}$, corresponding to the major primarily formed phase. For the alloy with $(x=0.2)$, two distinct exothermic reactions occurred, showing that two major phases were formed. The similar temperature range indicated a continuous solidification. For the alloys with increased titanium content $(x=0.5$ and 0.8$)$, the DSC cooling curves also showed two major exothermic reactions. However, the increasing temperature shift of the peaks indicated a changed solidification behaviour and chemical composition of the second major phases, while the primary phase precipitated at the same temperature. For the equimolar alloy $(x=1.0)$, a further peak appeared at a temperature of $1470 \mathrm{~K}$, showing that an additional phase was formed. The DSC cooling curve of the alloy with the highest titanium content $(x=1.5)$ only displayed two exothermic reactions, which can be ascribed to the two major phases also detected for the alloys with lower titanium content. No further peak of another phase visible in the SEM images (Figure 1f) appeared, indicating a small phase content or a similar solidification temperature.

For the assignment of phases, the resulting diffractograms of the XRD phase analyses are shown in Figure 3.

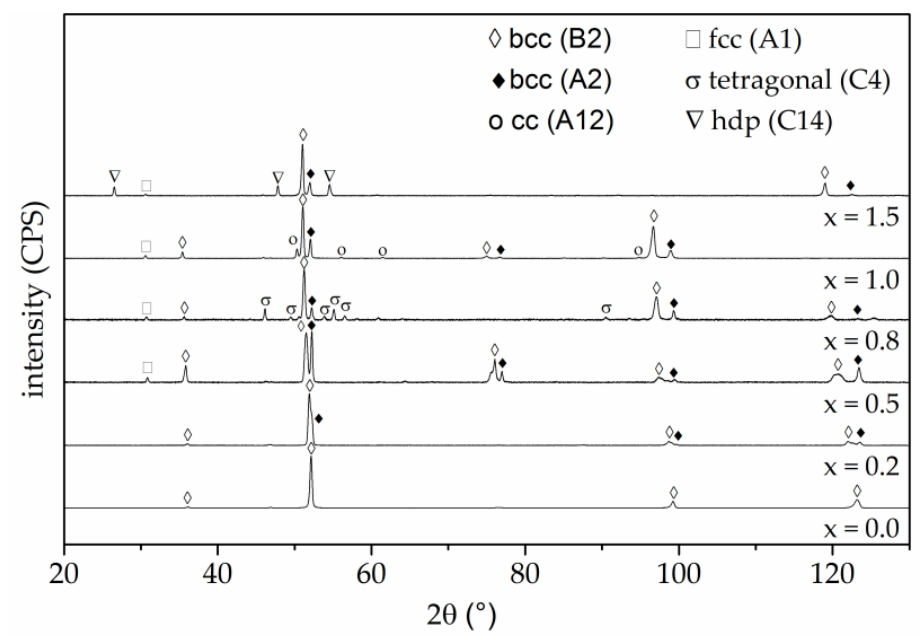

Figure 3. XRD diffractograms of arc-melted $\mathrm{AlCoCrFeNiTi}_{\mathrm{x}}$ samples. A single phase is formed for the alloy without titanium, whereas diffraction peaks of additional phases occur for an increased titanium content. Complex phases are formed for $\mathrm{x} \geq 0.8$. 
The diffraction diagram of the alloy without titanium $(x=0.0)$ exhibited high intensity diffraction peaks which could be ascribed to a chemically ordered bcc phase with B2 structure. Diffraction peaks of this phase appeared for all investigated alloys, which was in accordance with DSC results, revealing that this phase is the primary phase (PP). For all titanium containing alloys, the diffractograms showed an additional phase with a bcc structure: a chemically disordered bcc phase with A2 structure. This phase corresponded to the second exothermic reaction in the DSC measurements, and hence to the interdendritic phase (IP) in the alloys $x \geq 0.2$. The stabilisation of bcc phases due to a high aluminium content has been reported elsewhere in detail [19]. For the alloy with the lowest titanium content $(x=0.2)$, no additional phases were be detected. However, with increased titanium content further diffraction peaks occurred. For all alloys with a titanium content of $x \geq 0.5$, an additional peak at a diffraction angle of $31.0^{\circ}$ appeared. This diffraction angle could be ascribed to an fcc phase. Further diffraction peaks of this phase overlapped with the bcc (B2) phase. Previous investigations of the alloy system $\mathrm{Al}_{\mathrm{x}} \mathrm{CoCrFeNiTi}$ revealed the solidification of the fcc phase as a remainder in the cell walls [19]. The diffraction diagram of the alloy with a titanium content of $x=0.8$ exhibited several additional diffraction peaks, which can be assigned to a tetragonal $\sigma$ phase. This phase has also been detected by Moravcik et al. for the alloy AlCoCrFeNiTi 0.5 produced by spark plasma sintering (SPS). Microstructural investigations revealed the formation of this phase embedded in a mixture of other phases around a primary phase. However, subsequent heat treatment resulted in the dissolution of the $\sigma$ phase, showing that the formation of this phase sensitively depends on manufacturing conditions [25]. For the equimolar alloy $(x=1.0)$, no diffraction peaks of the $\sigma$ phase appeared. Additional peaks occurred, which can be ascribed to a centred cluster (cc) with A12 structure type. DSC results also revealed the formation of an additional phase, which solidifies as a remainder after the two major bcc phases and forms cell walls in the microstructure. This phase has been detected in the same alloy system in preliminary studies by Lindner et al. and for a high aluminium content (AlCoCrFeNiTi 1.5$)$, the formation of this phase could be suppressed [19]. The diffractogram of the alloy with the highest titanium content $(x=1.5)$ exhibited diffraction peaks which can be ascribed to the bcc (A2), bcc (B2) and an fcc phase. However, the diffraction peaks at $2 \theta=35.4^{\circ} ; 96.7^{\circ}$ and $98.9^{\circ}$ of these phases did not appear. This might be caused by the relatively coarse microstructure and texture of the samples due to the comparatively slow cooling conditions. The diffraction diagram did not exhibit peaks of the $\sigma$ or cc (A12) phase. Additional diffraction peaks can be ascribed to a hexagonal Laves phase ( $\mathrm{C} 14 / \mathrm{MgZn}_{2}$ type). A similar phase with slightly changed lattice parameters has been detected by Zhou et al. [20]. The present phases and corresponding major crystallographic information are summarised in Table 3.

Table 3. Summary of phases detected by XRD analyses for arc-melted AlCoCrFeNiTi $\mathrm{X}_{\mathrm{x}}$ samples.

\begin{tabular}{|c|c|c|c|c|c|c|c|}
\hline$x$ & Phase & Struktur-Bericht & Lattice & Structure & Pearson Symbol & Space Group & Lattice Parameter (Å) \\
\hline 0.0 & PP & B2 & bcc & $\mathrm{CsCl}$ & cP2 & $\operatorname{Pm} \overline{3} \mathrm{~m}(221)$ & 2.88 \\
\hline \multirow[b]{2}{*}{0.2} & PP & B2 & bcc & $\mathrm{CsCl}$ & $\mathrm{cP} 2$ & $\operatorname{Pm} \overline{3} \mathrm{~m}(221)$ & 2.89 \\
\hline & IP & A2 & bcc & W & $\mathrm{cI} 2$ & $\operatorname{Im} \overline{3} \mathrm{~m}(229)$ & 2.87 \\
\hline \multirow{3}{*}{0.5} & PP & B2 & $\mathrm{bcc}$ & $\mathrm{CsCl}$ & cP2 & $\operatorname{Pm} \overline{3} \mathrm{~m}(221)$ & 2.92 \\
\hline & IP & A2 & bcc & W & $\mathrm{cI} 2$ & $\operatorname{Im} \overline{3} \mathrm{~m}(229)$ & 2.87 \\
\hline & $\mathrm{CW}$ & A1 & fcc & $\mathrm{Cu}$ & cF4 & Fm̄m (225) & 5.82 \\
\hline \multirow{4}{*}{0.8} & PP & B2 & bcc & $\mathrm{CsCl}$ & cP2 & $\operatorname{Pm} \overline{3} \mathrm{~m}(221)$ & 2.92 \\
\hline & IP & A2 & bcc & W & cI2 & $\operatorname{Im} \overline{3} \mathrm{~m}(229)$ & 2.87 \\
\hline & $\mathrm{CW}$ & A1 & fcc & $\mathrm{Cu}$ & $\mathrm{cF} 4$ & $\operatorname{Fm} \overline{3} \mathrm{~m}(225)$ & 5.85 \\
\hline & $\mathrm{CW}$ & $\mathrm{C} 4$ & tetragonal & $\mathrm{TiO}_{2}$ & tP6 & $\mathrm{P}_{2} / \mathrm{mnm}(136)$ & $\begin{array}{l}\mathrm{a}=8.80 \\
\mathrm{c}=4.56\end{array}$ \\
\hline \multirow{4}{*}{1.0} & PP & B2 & bcc & $\mathrm{CsCl}$ & $\mathrm{cP} 2$ & $\operatorname{Pm} \overline{3} \mathrm{~m}(221)$ & 2.93 \\
\hline & IP & A2 & bcc & $\mathrm{W}$ & cI2 & $\operatorname{Im} \overline{3} \mathrm{~m}(229)$ & 2.88 \\
\hline & $\mathrm{CW}$ & A1 & fcc & $\mathrm{Cu}$ & $\mathrm{cF} 4$ & $\operatorname{Fm} \overline{3} \mathrm{~m}(225)$ & 5.87 \\
\hline & $\mathrm{CW}$ & A12 & $\mathrm{cc}$ & $\alpha-\mathrm{Mn}$ & cI58 & $\mathrm{I} \overline{4} 3 \mathrm{~m}(217)$ & 8.92 \\
\hline \multirow{4}{*}{1.5} & PP & B2 & bcc & $\mathrm{CsCl}$ & cP2 & $\operatorname{Pm} \overline{3} \mathrm{~m}(221)$ & 2.94 \\
\hline & IP & A2 & bcc & W & cI2 & $\operatorname{Im} \overline{3} \mathrm{~m}(229)$ & 2.88 \\
\hline & $\mathrm{CW}$ & A1 & fcc & $\mathrm{Cu}$ & $\mathrm{cF} 4$ & $\operatorname{Fm} \overline{3} \mathrm{~m}(225)$ & 5.87 \\
\hline & $\mathrm{CW}$ & $\mathrm{C} 14$ & hexagonal & $\mathrm{MgZn}_{2}$ & hP12 & $\mathrm{P}_{3} / \mathrm{mmc}(194)$ & $\begin{array}{l}\mathrm{a}=4.80 \\
\mathrm{c}=7.81\end{array}$ \\
\hline
\end{tabular}


In addition to the formation of further phases, a shift of lattice parameters was observed with increasing titanium content. The lattice parameters of the bcc (B2) phase and the fcc (A1) phase were slightly increased. This behaviour indicated that more titanium with a large atomic radius was resolved in these phases.

\subsection{Hardness and Wear Behaviour}

The influence of the titanium content on the average microhardness HV0.5 was investigated. The results are summarised in Figure 4.

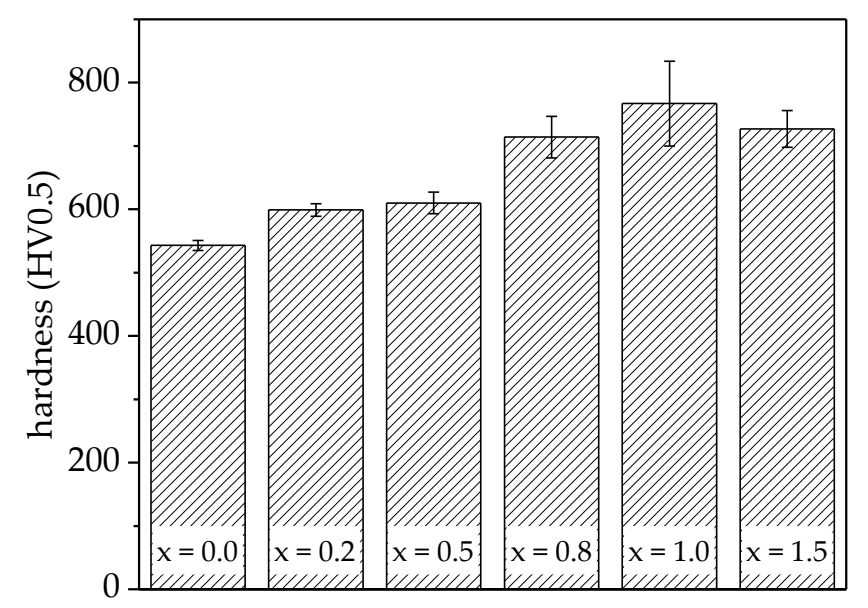

Figure 4. Microhardness of arc-melted AlCoCrFeNiTi $i_{x}$ samples. Microhardness increases with titanium content, reaching a maximum of 770 HV0.5 for the equimolar alloy.

For the alloy without titanium $(x=0.0)$, an average microhardness of 550 HV0.5 was measured. With increasing titanium content, an increase of microhardness was observed, reaching a maximum for the equimolar composition with a microhardness of $770 \mathrm{HV} 0.5$. The increasing hardness indicated the formation of additional phases, which was in accordance with microstructural investigations and phase analyses. Furthermore, solid solution strengthening contributes to an increase of hardness-an increase of lattice parameters could be proven for the bcc (B2) and fcc (A1) phases. However, for the alloy with the highest titanium content $(x=1.5)$, a reduced microhardness of 730 HV0.5 was measured, which might be a result of the increased presence of cavities and shrinkage porosity in that alloy.

The wear behaviour was investigated under adhesive, oscillating, and abrasive wear conditions in ball-on-disk, oscillating wear, and scratch tests. The results are summarised in Figure 5.
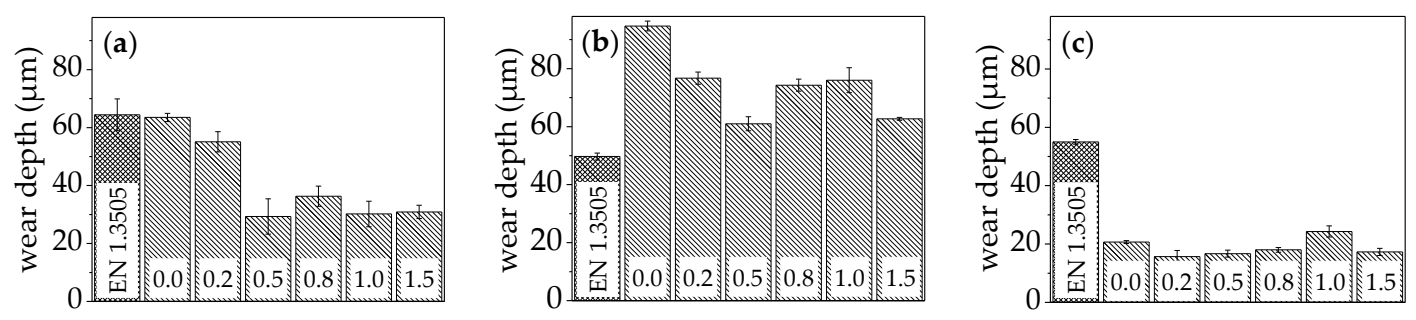

Figure 5. Wear depths of bearing steel EN 1.3505 and AlCoCrFeNiTi ${ }_{x}$ in: (a) Ball-on-disk; (b) Oscillating wear and (c) Scratch tests. The wear depths of $\mathrm{AlCoCrFeNiTi}_{\mathrm{x}}$ are decreased in comparison to EN 1.3505, except under oscillating wear conditions. Overall, the best results are obtained for $\mathrm{x}=0.5$.

The investigation of the wear behaviour in the ball-on-disk test revealed a high wear depth for the alloy without titanium $(x=0.0)$. With the addition of titanium $(x=0.2)$, a slight decrease of wear depth could be achieved. Further increase to $x=0.5$ resulted in a distinct decrease of wear depth. The alloy 
$\mathrm{x}=0.5$ exhibited a multiphase character, only comprising cubic phases. In comparison to the alloys with lower titanium content, the microhardness was increased, which enhanced wear resistance in ball-on-disk tests. However, further increase of titanium content did not cause a reduction of wear depth or an improvement of the wear resistance. Phase analyses revealed the formation of additional complex phases reducing wear resistance. All samples containing titanium exhibited a lower wear depth in comparison with the bearing steel EN 1.3505, and hence a higher wear resistance in the ball-on-disk test.

In the oscillating wear tests, the highest wear depth was measured for the alloy without titanium $(x=0.0)$. Adding minor amounts of titanium resulted in a decrease of the wear depth. For the sample $x=0.5$, the lowest wear depth was measured, showing that a multiphase character only comprising cubic phases was advantageous under oscillating wear condition. The further addition of titanium led to an increase of the wear depth. Additional tetragonal or cc phases did not contribute to an improvement of wear resistance. For the alloy with the highest titanium content $(x=1.5)$, a low wear depth was measured, which was in the range of the alloy with $x=0.5$. In comparison with bearing steel EN 1.3505, all investigated samples exhibited a higher wear depth, and thereby lower wear resistance under oscillating wear conditions.

Under abrasive tribological conditions in the scratch tests, the lowest wear depth was measured for the sample with a titanium content of $x=0.2$. With an increase in titanium content, the wear depth slightly increased. The highest wear depth was measured for the equimolar alloy $(x=1.0)$. In comparison to the bearing steel EN 1.3505, all investigated samples exhibit a distinctly lower wear depth and thereby higher wear resistance. The wear tracks of all samples were investigated by optical microscopy. In Figure 6 images of the sample surface where the highest load was applied in the progressive mode scratch test are shown.
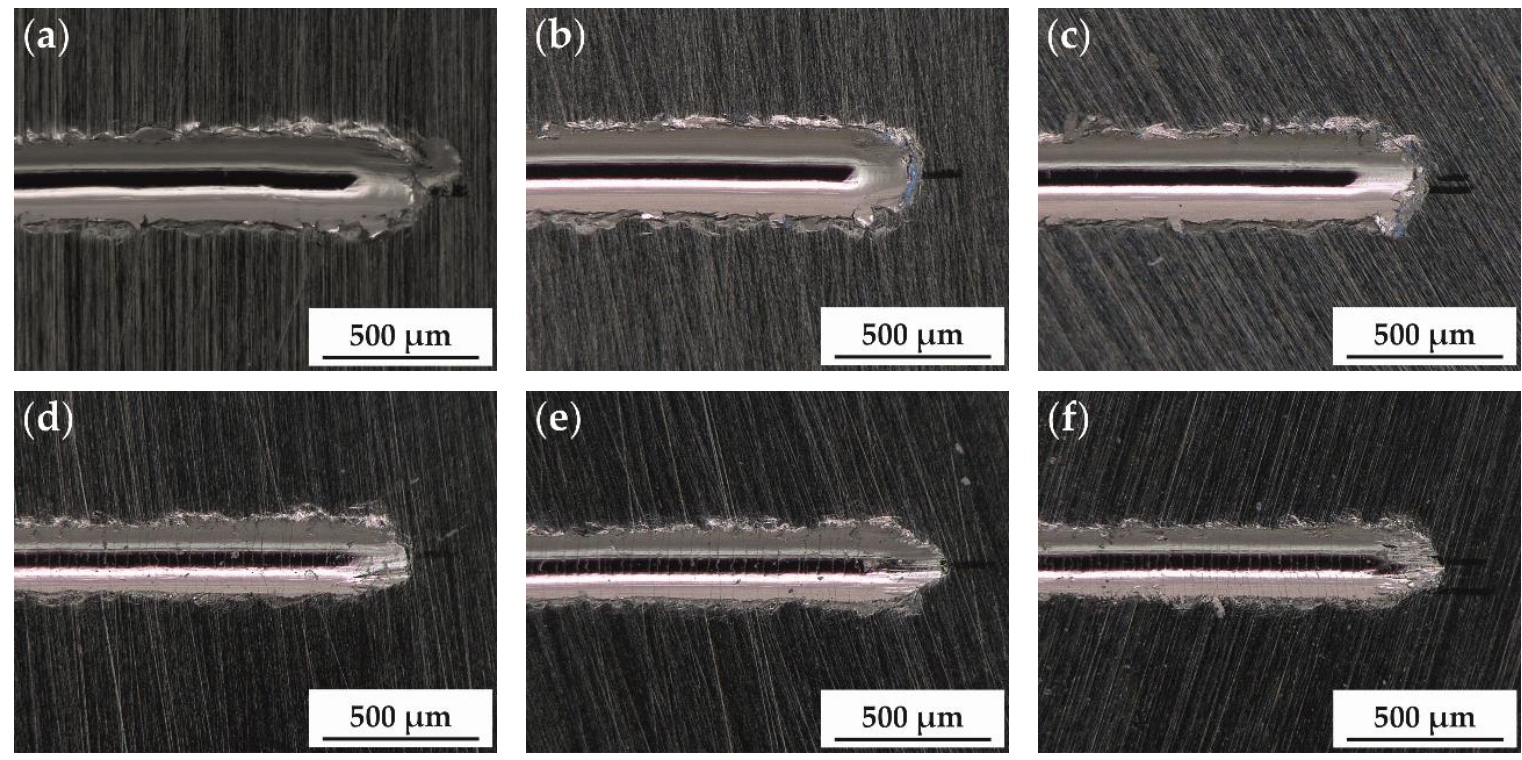

Figure 6. Surface of the arc-melted AlCoCrFeNiTix samples: $(\mathbf{a}) \mathrm{x}=0.0 ;(\mathbf{b}) \mathrm{x}=0.2 ;(\mathbf{c}) \mathrm{x}=0.5 ;(\mathbf{d}) \mathrm{x}=0.8$; (e) $\mathrm{x}=1.0 ;(\mathrm{f}) \mathrm{x}=1.5$ after progressive mode scratch test. Ductile behaviour occurs for $\mathrm{x} \leq 0.5$, whereas cracks or spalling of material are visible for $\mathrm{x} \geq 0.8$.

The investigation of the surface after scratch test under abrasive conditions reveals no cracks or spalling of material along the main scratch for the sample without titanium $(x=0.0)$ and the two samples with the lowest titanium content $(x=0.2 ; x=0.5)$. However, spalling of material and distinct secondary cracks perpendicular to the main scratch can be observed for all samples with a titanium content exceeding $x=0.5$. The formation of secondary cracks and spalling of material 
indicated the brittle behaviour of these alloys, which is caused by the formation of additional, complex phases-tetragonal, cc and a hexagonal Laves phase for a titanium content $x \geq 0.8$. These phases possess low numbers of slip systems, which results in reduced ductility.

\section{Summary and Conclusions}

The influence of the alloying element titanium was studied in detail in the alloy system $\mathrm{AlCoCrFeNiTi}_{\mathrm{x}}$. For the alloy without titanium $(\mathrm{x}=0.0)$, a single chemically ordered bcc phase with B2 structure is formed. In contrast, a multiphase microstructure was revealed for all titanium-containing alloys. With an increase of titanium content, an increase of heterogeneity of the microstructure is observed. Furthermore, the hardness can be distinctly increased, whereas the maximum hardness is achieved for the equimolar composition. Phase analyses prove the formation of two major bcc phases for all titanium-containing samples. One chemically ordered bcc phase with B2 structure and one chemically disordered bcc phase with A2 structure is formed. With an increase in titanium content, additional phases occur. For $\mathrm{x} \geq 0.5$ a minor fraction of an fcc phase was detected. A further increase in titanium content results in additional, more complex phases. This could also be proved by analysing the solidification behaviour. Analyses of the lattice parameters revealed a shift to bigger values with increasing titanium content, especially for the bcc (B2) and the fcc (A1) phase. The alloy system $\mathrm{AlCoCrFeNiTi}_{x}$ exhibits an increased wear resistance in comparison with the bearing steel EN 1.3505, except under oscillating wear conditions.

Correlations between phase composition, microstructure, and wear resistance can be concluded. Microstructure design for high wear resistance requires cubic phases. Hereby, a multiple bcc/fcc phase character exhibits an advantageous behaviour. Complex phases (cc and tetragonal) increase the hardness, but should be avoided in order to achieve a high wear resistance, as the presence of these phases causes increased brittleness. $\mathrm{AlCoCrFeNiTi}_{0.5}$ is a promising candidate for wear protection applications in both bulk and coating materials.

Author Contributions: M.L. and T.L. (Thomas Lindner) conceived and designed the experiments. M.L., T.L. (Thomas Lindner) and T.M. performed the experiments, analysed the data, and wrote the paper. T.L. (Thomas Lampke) directed the research, and contributed to the discussion and interpretation of the results.

Acknowledgments: The publication costs of this article were funded by the German Research Foundation/DFG and the Chemnitz University of Technology in the funding programme Open Access Publishing. The authors thank Benjamin Sattler for sample manufacturing, Marc Pügner for conducting the XRD measurements and Thomas Uhlig for conducting the DSC measurements.

Conflicts of Interest: The authors declare no conflict of interest.

\section{References}

1. Yeh, J.-W.; Lin, S.-J.; Chin, T.-S.; Gan, J.-Y.; Chen, S.-K.; Shun, T.-T.; Tsau, C.-H.; Chou, S.-Y. Formation of simple crystal structures in $\mathrm{Cu}-\mathrm{Co}-\mathrm{Ni}-\mathrm{Cr}-\mathrm{Al}-\mathrm{Fe}-\mathrm{Ti}-\mathrm{V}$ alloys with multiprincipal metallic elements. Metall. Mater. Trans. A 2004, 35, 2533-2536. [CrossRef]

2. Cantor, B.; Chang, I.; Knight, P.; Vincent, A. Microstructural development in equiatomic multicomponent alloys. Mater. Sci. Eng. A 2004, 375-377, 213-218. [CrossRef]

3. Murty, B.S.; Yeg, J.-W.; Ranganathan, S. High-Entropy Alloys; Elsevier: Amsterdam, The Netherlands, 2014.

4. Gao, M.C.; Yeh, J.-W.; Liaw, P.K.; Zhang, Y. High-Entropy Alloys: Fundamentals and Applications, 1st ed.; Springer International Publishing: Cham, Switzerland, 2016.

5. Miracle, D.B.; Senkov, O.N. A critical review of high entropy alloys and related concepts. Acta Mater. 2017, 122, 448-511. [CrossRef]

6. Zhang, W.; Liaw, P.K.; Zhang, Y. Science and technology in high-entropy alloys. Sci. China Mater. 2018, 61, 2-22. [CrossRef]

7. Miracle, D.B.; Miller, J.D.; Senkov, O.N.; Woodward, C.; Uchic, M.D.; Tiley, J. Exploration and Development of High Entropy Alloys for Structural Applications. Entropy 2014, 16, 494-525. [CrossRef]

8. Tsai, M.-H.; Yeh, J.-W. High-Entropy Alloys: A Critical Review. Mater. Res. Lett. 2014, 2, 107-123. [CrossRef] 
9. Singh, S.; Wanderka, N.; Murty, B.S.; Glatzel, U.; Banhart, J. Decomposition in multi-component AlCoCrCuFeNi high-entropy alloy. Acta Mater. 2011, 59, 182-190. [CrossRef]

10. Soare, V.; Mitrica, D.; Constantin, I.; Badilita, V.; Stoiciu, F.; Popescu, A.-M.; Carcea, I. Influence of remelting on microstructure, hardness and corrosion behaviour of AlCoCrFeNiTi high entropy alloy. Mater. Sci. Technol. 2015, 10, 1194-2200. [CrossRef]

11. Löbel, M.; Lindner, T.; Kohrt, C.; Lampke, T. Processing of AlCoCrFeNiTi high entropy alloy by atmospheric plasma spraying. IOP Conf. Ser. Mater. Sci. Eng. 2017, 181, 12015. [CrossRef]

12. Wang, R.; Zhang, K.; Davies, C.; Wu, X. Evolution of microstructure, mechanical and corrosion properties of AlCoCrFeNi high-entropy alloy prepared by direct laser fabrication. J. Alloys Compd. 2017, 694, 971-981. [CrossRef]

13. Wang, Y.P.; Li, B.S.; Ren, M.X.; Yang, C.; Fu, H.Z. Microstructure and compressive properties of $\mathrm{AlCrFeCoNi}$ high entropy alloy. Mater. Sci. Eng. A 2008, 491, 154-158. [CrossRef]

14. Kumar, A.; Gupta, M. An Insight into Evolution of Light Weight High Entropy Alloys: A Review. Metals 2016, 6, 199. [CrossRef]

15. Cao, T.; Shang, J.; Zhao, J.; Cheng, C.; Wang, R.; Wang, H. The influence of Al elements on the structure and the creep behavior of $\mathrm{Al}_{\mathrm{x}} \mathrm{CoCrFeNi}$ high entropy alloys. Mater. Let. 2016, 164, 344-347. [CrossRef]

16. Li, C.; Li, J.C.; Zhao, M.; Jiang, Q. Effect of aluminium contents on microstructure and properties of $\mathrm{Al}_{\mathrm{x}} \mathrm{CoCrFeNi}$ alloys: 16th International Symposium on Metastable, Amorphous and Nanostructured Materials. J. Alloys Compd. 2010, 504, 515-518. [CrossRef]

17. Chou, H.-P.; Chang, Y.-S.; Chen, S.-K.; Yeh, J.-W. Microstructure, thermophysical and electrical properties in $\mathrm{Al}_{\mathrm{x}} \mathrm{CoCrFeNi}(0 \leq \mathrm{x} \leq 2)$ high-entropy alloys. Mater. Sci. Eng. B Adv. 2009, 163, 184-189. [CrossRef]

18. Tung, C.-C.; Yeh, J.-W.; Shun, T.-T.; Chen, S.-K.; Huang, Y.-S.; Chen, H.-C. On the elemental effect of AlCoCrCuFeNi high-entropy alloy system. Mater. Lett. 2007, 61, 1-5. [CrossRef]

19. Lindner, T.; Löbel, M.; Mehner, T.; Dietrich, D.; Lampke, T. The Phase Composition and Microstructure of $\mathrm{Al}_{\mathrm{x}} \mathrm{CoCrFeNiTi}$ Alloys for the Development of High-Entropy Alloy Systems. Metals 2017, 7, 162. [CrossRef]

20. Zhou, Y.J.; Zhang, Y.; Wang, Y.L.; Chen, G.L. Solid solution alloys of AlCoCrFeNiTi $\mathrm{x}_{\mathrm{x}}$ with excellent room-temperature mechanical properties. Appl. Phys. Lett. 2007, 90, 181904. [CrossRef]

21. Chen, M.R.; Lin, S.J.; Yeh, J.W.; Chen, S.K.; Huang, Y.S.; Tu, C.P. Microstructure and Properties of $\mathrm{Al}_{0.5} \mathrm{CoCrCuFeNiTi}$ (x=0-2.0) High-Entropy Alloys. Mater. Trans. 2006, 47, 1395-1401. [CrossRef]

22. Chuang, M.-H.; Tsai, M.-H.; Wang, W.-R.; Lin, S.-J.; Yeh, J.-W. Microstructure and wear behavior of $\mathrm{Al}_{\mathrm{x}} \mathrm{Co}_{1.5} \mathrm{CrFeNi}_{1.5} \mathrm{Ti}_{\mathrm{y}}$ high-entropy alloys. Acta Mater. 2011, 59, 6308-6317. [CrossRef]

23. Yu, Y.; Wang, J.; Li, J.; Kou, H.; Liu, W. Characterization of BCC phases in AlCoCrFeNiTi $\mathrm{A}_{\mathrm{x}}$ high entropy alloys. Mater. Lett. 2015, 138, 78-80. [CrossRef]

24. Wang, Y.; Ma, S.; Chen, X.; Shi, J.; Zhang, Y.; Qiao, J. Optimizing Mechanical Properties of AlCoCrFeNiTix High-Entropy Alloys by Tailoring Microstructures. Acta Metall. Sin. 2013, 26, 277-284. [CrossRef]

25. Moravcik, I.; Cizek, J.; Gavendova, P.; Sheikh, S.; Guo, S.; Dlouhy, I. Effect of heat treatment on microstructure and mechanical properties of spark plasma sintered $\mathrm{AlCoCrFeNiTi}{ }_{0.5}$ high entropy alloy. Mater. Lett. 2016, 174, 53-56. [CrossRef]

(C) 2018 by the authors. Licensee MDPI, Basel, Switzerland. This article is an open access article distributed under the terms and conditions of the Creative Commons Attribution (CC BY) license (http://creativecommons.org/licenses/by/4.0/). 